\author{
Robert A. Gross, MD, PhD, FAAN \\ Editor-in-Chief, Neurology ${ }^{\circledR}$
}

\section{Subcortical atrophy and cognition: Sex effects in multiple sclerosis}

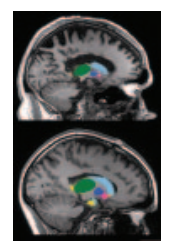

Structural MRI and neuropsychological evaluations were performed in 120 patients ( 80 women) and 50 controls (30 women), part of an early inception cohort, 6 years after diagnosis. Male sex was an important predictor of worse cognitive performance and higher regional atrophy, which should be taken into account in future research and treatment strategies.

See p. 1754

From editorialists Fisher \& Benedict: "Regardless of the sex question, explanations for why the thalamus is affected so early in MS, and why the thalamus is such an important structure for clinical presentation in MS, remain elusive."

See p. 1748

\section{Neurologist-associated reduction in PD-related hospitalizations and health care expenditures}

This study identified 24,929 incident Parkinson disease (PD) cases; 13,489 had neurologist care, with 9,112 PD-related hospitalizations. Regular neurologist care in PD lowers risk of hospitalization and rehospitalization, which may reflect an improved ability of neurologists to prevent, recognize, or treat PD complications.

See p. 1774

\section{Age at stroke: Temporal trends in stroke incidence in a} large, biracial population

The authors studied temporal trends in stroke incidence in younger adults (age 20-54), which increased over time. Strokes in young patients have greater lifetime burden of disability, so risk factors for stroke in young adults, not just in older patients, must be identified as potential modifiable contributors to counter the rising incidence.

See p. 1781; Editorial, p. 1752

\section{Cerebral hemodynamics and cognitive performance in} bilateral asymptomatic carotid stenosis

Three hundred thirty-three participants (65\% male) were evaluated: 127 with bilateral asymptomatic carotid stenosis (ACS), $73 / 77$ with left/right unilateral ACS, and 56 without carotid stenosis. Patients with bilateral and unilateral ACS showed greater cognitive impairment than those with no carotid disease. Impaired cognition was correlated with altered cerebral hemodynamics.

See p. 1788

\section{Absence of early epileptiform abnormalities predicts lack of seizures on continuous EEG}

The authors evaluated 242 patients without a prior generalized convulsive seizure or active epilepsy who underwent continuous EEG monitoring for detection of nonconvulsive seizures or evaluation of unexplained altered mental status. During the first 4 hours of recording, no seizures were detected in patients without epileptiform abnormalities.

See p. 1796

Neuroprotective lifestyles and the aging brain: Activity, atrophy, and white matter integrity

Participation in physical activity and activities of a social or intellectual nature were assessed by self-report in a cohort of adults age 70 , with structural brain biomarkers measured at age 73. A higher level of physical activity potentially protects the brain against age-related deterioration and should be tested in clinical trials.

See p. 1802

Injury markers predict time to dementia in subjects with $\mathrm{MCl}$ and amyloid pathology

The authors studied 110 patients with mild cognitive impairment with abnormal CSF $\beta$-amyloid - $_{1-42}$ and a mean Mini-Mental State Examination score of $26.3 \pm 2.8$. During a mean follow- up of $2.2 \pm 1.0$ years, 63 participants (57\%) progressed to Alzheimer disease-type dementia. Abnormal CSF t-tau concentration and hippocampal atrophy predicted time to dementia.

See p. 1809

VIEWS \& REVIEWS

Outcomes after thrombolysis in AIS according to prior statin use: A registry and review

The impact of prior statin use on outcomes after thrombolysis is controversial. This meta-analysis included 7,044 strokes, showing that statin use was not associated with either favorable or unfavorable outcomes, including symptomatic intracranial hemorrhage. Statin therapy should not be considered as a contraindication to thrombolysis.

See p. 1817

NB: "Mouse Brain Kaleidoscope," see p. 1829. To check out other Visions, point your browser to www.neurology.org.

Podcasts can be accessed at www.neurology.org 


\title{
Neurology
}

\author{
Spotlight on the October 23 Issue \\ Robert A. Gross \\ Neurology 2012;79;1747 \\ DOI 10.1212/WNL.0b013e318273cebf
}

This information is current as of October 22, 2012

\section{Updated Information \&}

Services

Permissions \& Licensing

Reprints including high resolution figures, can be found at: http://n.neurology.org/content/79/17/1747.full

Information about reproducing this article in parts (figures,tables) or in its entirety can be found online at:

http://www.neurology.org/about/about_the_journal\#permissions

Information about ordering reprints can be found online:

http://n.neurology.org/subscribers/advertise

Neurology ${ }^{\circledR}$ is the official journal of the American Academy of Neurology. Published continuously since 1951, it is now a weekly with 48 issues per year. Copyright Copyright (? 2012 by AAN Enterprises, Inc.. All rights reserved. Print ISSN: 0028-3878. Online ISSN: 1526-632X.

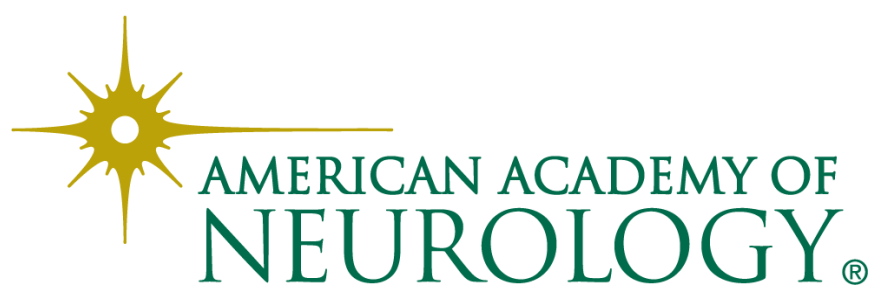

